\title{
Educação de meninas na América portuguesa: das instituições de reclusão à vida em sociedade (séculos XVIII e início do XIX)
}

\section{The education of girls in Portuguese America; from institutions of reclusion to life in society ( $18^{\text {th }}$ and early $19^{\text {th }}$ Centuries)}

\author{
Leila Mezan Algranti*
}

\begin{abstract}
Resumo
A exemplo do que sucedia em Portugal, a educação das meninas na America portuguesa, envolvia aspectos mais amplos do que aprender as primeiras letras. Com base em documentos de caráter normativo, tais como: tratados de educação, planos de estudos e manuais de boas maneiras e civilidade pretende-se refletir sobre as representações da sociedade em relação às mulheres e o que se esperava que elas aprendessem para melhor desempenharem suas funções e atuarem em sociedade.
\end{abstract}

Palavras chaves: Educação feminina. Civilidade. Gênero.

\begin{abstract}
As it happened in Portugal, the education of girls in Portuguese America involved much more than learning the first letters. Based in documents of a normative nature, such as education treatises, study plans and manuals of good manners and civility we will try to reflect on the representations that society created regarding women and what they were expected to learn in order to better execute their chores and act in society.
\end{abstract}

Keywords: Feminine education. Civility. Gender.

\section{Introdução}

Apesar do crescente interesse pela história da leitura e da escrita na América portuguesa, o tema da instrução feminina tem sido pouco contemplado pela historiografia colonial, com destaque para alguns trabalhos centrados em estabelecimentos específicos de clausura e destinados ao aco-

\footnotetext{
* Doutora em História Social pela Universidade de São Paulo. Professora titular de História do Brasil na Universidade Estadual de Campinas. E-mail: algranti@unicamp.br
} 
lhimento de mulheres por motivos diversos. ${ }^{1}$ A educação das meninas (e dos meninos também) no entanto, envolvia aspectos mais amplos do que aprender as primeiras letras e por isso é também frequentemente abordada por historiadores dedicados ao estudo das normas ou regras de comportamento social, os quais se apoiam -- na maior parte das vezes -- em manuais de civilidade disponíveis para a época. ${ }^{2}$ Estes, embora não apresentassem um programa pedagógico propriamente dito, possuíam caráter didático, pois ensinavam aos seus leitores desde normas de etiqueta a procedimentos de ordem moral e religiosa. Nesse sentido, são fontes extremamente ricas para refletirmos sobre as representações da sociedade em relação às mulheres e o que se esperava que aprendessem para melhor desempenharem suas funções e atuarem em sociedade.

Dessa forma, é possível perceber que quando se aborda a questão da educação feminina no período colonial, três aspectos são geralmente destacados de forma conjunta ou isolada: os espaços onde se desenvolvia o processo de educação (institucional ou doméstica); o programa pedagógico destinado às meninas (plano de estudos); e os princípios da educação feminina, ou seja, as justificativas para educá-las. São esses três aspectos, portanto, que eu gostaria de comentar brevemente, a fim de refletir sobre a educação das meninas na América portuguesa entre o século XVIII e o início do século XIX.

\section{Educação institucional e plano de estudos para meninas}

Até o século XVIII o que se observa na América portuguesa é a ausência de espaços institucionais especializados para a instrução das meninas como conventos, escolas e institutos de ensino. A partir desse momento, porém, assiste-se à fundação de vários recolhimentos femininos. Tratava-se de instituições de reclusão -- leigas ou religiosas- as quais assumiam múltiplas funções, servindo como espaços de devoção, de educação e, em alguns casos,

\footnotetext{
${ }^{1}$ Ver por exemplo: ROCHA, Adair José dos Santos. A Educação Feminina nos século XVIII e XIX - Intenções dos bispos para o Recolhimento das Macaúbas. Dissertação de mestrado. Belo Horizonte, UFMG, 2008; Luiz Carlos Villalta (org.), dossiê "Bibliotecas, leitura e educação" In: Revista do Arquivo Público Mineiro, ano XLVIII, jan-dez 2012, p. 20-97; OLIVEIRA, Claudia Ferreira de. Manuais de civilidade e tratados sobre a educação portugueses: luzes sobre a educação feminina em Minas Gerais. In: V Congresso de Ensino e Pesquisa de História da Educação em Minas Gerais. Acesso em 14/11/2014 http://www.congressods.com.br/vcopehe/index.php/iinstitucoes-educacionais-e-ou-cientificas

${ }^{2}$ Sobre os manuais de civilidade ver o estudo de REVEL, Jacques. Os usos da civilidade. In: ARIÉS, Philippe e CHARTIER, Roger. Da Renascença ao Século das Luzes, vol. 3 da História da Vida Privada, coleção dirigida por Philippe Ariés e Georges Duby. São Paulo: Companhia das Letras, 1996, p.169-210.
} 
de correção de mulheres. Em Minas Gerais, por exemplo, iniciou-se em 1714, a construção de uma ermida que daria origem ao recolhimento das Macaúbas. Em 1789, o estabelecimento foi confirmado como local voltado para a educação por D. Maria I, quando a Coroa recusou definitivamente o pedido para que a casa se tornasse um convento, sendo redigido um plano de estudos para suas habitantes. ${ }^{3}$ Embora o estabelecimento nunca tenha abandonado o caráter religioso que inspirou sua fundação, a tradição educativa acompanhou a história da instituição e, em meados do século XIX, Macaúbas transformou-se no famoso colégio para meninas da elite mineira. Foi somente no início do século seguinte que a casa atingiu o objetivo para o qual havia sido fundada, tornando-se um convento de religiosas professas franciscanas. ${ }^{4}$

Outro exemplo comumente citado de espaço educacional feminino é o Recolhimento de Nossa Senhora da Glória, em Pernambuco, fundado pelo bispo ilustrado Azeredo Coutinho, no final do século XVIII e que também foi uma instituição voltada para o ensino, contendo um plano de estudos, redigido pelo próprio bispo, em $1798 .{ }^{5}$ Havia ainda nessa época recolhimentos para órfãs ligados às irmandades da Misericórdia, como os da Bahia e do Rio de Janeiro que, na condição de casas para meninas órfãs, assumiram o papel de locais de educação, a fim de prepará-las para o casamento. ${ }^{6}$ Os recolhimentos para mulheres arrependidas ou convertidas -- como o de Itaipu, no Rio de Janeiro -- também possuíam uma função educativa e ou "corretiva". ${ }^{7}$ Em todos esses estabelecimentos, independentemente dos motivos de sua fundação, havia horários dedicados tanto à instrução religiosa de suas habitantes quanto ao desenvolvimento das habilidades de leitura e escrita.

Dessa forma, pode-se dizer que ao longo da colonização portuguesa na América, os recolhimentos femininos se configuraram como espaços

\footnotetext{
${ }^{3}$ Alvará Régio de confirmação de Macaúbas, Arquivo Nacional Rio de Janeiro, Mesa do Desembargo do Paço, cx 130, pacote 2, doc.5

${ }^{4}$ Sobre a fundação do Recolhimento de Nossa Senhora da Conceição de Macaúbas e as funções múltiplas que este e outros recolhimentos femininos adquiriram no século XVIII na Colônia ver: ALGRANTI , Leila M. Honradas e Devotas: Mulheres da Colônia condição feminina nos conventos do Sudeste do Brasil 17501822, 2ª . Brasília/Rio de Janeiro: Ed. EDunb/ José Olympio, 1998, p. 72-82.

${ }^{5}$ COUTINHO, D. José Joaquim da Cunha de Azeredo. Estatutos do Recolhimento de Nossa Senhora da Glória do lugar da Boa Vista de Pernambuco. Lisboa: Academia Real de Letras, 1798. Para uma análise mais abrangente desse recolhimento ver ALMEIDA, Suely. 0 sexo devoto: Normatização e resistência feminina no império português (XVI - XVIII). Recife: Editora Universitária UFPE, 2005.

${ }^{6}$ Ver sobre o assunto; ALGRANTI, op. cit., p. 247-258; e também GANDELMAN, Luciana. Entre a cura das almas e o remédio das vidas: o recolhimento de órfãs da Santa Casa de Misericórdia do Rio de Janeiro e a caridade para com as mulheres (1739-1830). Rio de Janeiro: Secretaria Municipal das Culturas, 2008.

${ }^{7}$ Sobre o recolhimento de Itaipu, ver: ALGRANTI, op. cit., p.101-106.
} 
institucionais privilegiados nos quais se poderia ter uma educação formal para meninas. O conteúdo do que deveria ser ensinado a elas nos leva ao segundo aspecto comumente tratado por aqueles que se interessaram pelo tema da educação feminina no período colonial, ou seja, o currículo ou plano de estudos.

Nos recolhimentos da América portuguesa, a exemplo do que sucedia em Portugal e em outros países da Europa, o plano de estudos para as meninas era diferente daquele destinado ao meninos. Inspirado no ideal da Luzes, quando a educação foi elevada a um patamar de destaque e se tornou responsável pelo progresso das nações, a proposta de educação das mulheres acabou também por ganhar atenção. Nos estabelecimentos para meninas certamente o conteúdo a ser transmitido não seria equivalente ao dos meninos, pois além das diferenças de gênero se constituírem como um fator importante de distinção nesse campo, jamais passou pela mente dos filósofos ilustrados que todos os indivíduos deveriam receber a mesma educação. Os dois grandes representantes do movimento ilustrado em Portugal e que se debruçaram sobre os problemas da educação - Luis Verney (1713-1792) e Antônio Ribeiro Sanches (1699-1782) não fugiram a essa regra. É célebre a citação de Sanches sobre a desigualdade social na educação: "que filho de pastor quererá ter aquele ofício de seu pai se à idade de 12 anos soubesse ler e escrever? perguntou ele nas Cartas para a educação da mocidade. ${ }^{8}$

Apesar de ressalvas desse tipo, ambos os autores mencionados dedicaram atenção ao tema da educação feminina influenciados, possivelmente, pelo plano de estudos idealizado por Fénelon (1651 - 1715) para a educação de meninas nobres, em seu célebre tratado L' Education des Filles (1687). ${ }^{9}$ Verney tratou do assunto na famosa carta número dezesseis que encerra o Verdadeiro Método de Estudar (1742) e que tem como apêndice um plano para a educação das meninas, no qual discorreu sobre as disciplinas que deveriam compor o currículo das jovens portuguesas..$^{10}$ Ribeiro Sanches, por sua vez, nas Cartas sobre a Educação da Mocidade (1763), propôs a criação de recolhimentos ou de escolas com clausura para ali se educarem as filhas dos fidalgos

\footnotetext{
${ }^{8}$ SANCHES, Nunes Ribeiro. Cartas sobre a educação da mocidade. In: Obras (1760). Coimbra: Universidade de Coimbra, 1959, p. 288

${ }^{9}$ FÉNELON, François. De l'Education des Filles, ATHENA e-text, version rtf. Numérisation et correction: Selamawit Abebe, Flor Alen Sanchez, Stéphanie Equey. http://athena.unige.ch/athena/fenelon/fen_fill.html. Acesso em 14/11/2014.

${ }^{10}$ VERNEY, Luis Antônio. O Verdadeiro método de estudar. (1746) Prefácio e notas de Joaquim Ferreira. Porto: Domingos Borreia Editor, s/d.
} 
porque segundo ele, "as mães e o sexo feminino são os primeiros mestres do nosso [sexo]. ${ }^{11}$

Mas há outro documento sobre a educação feminina atribuído a Ribeiro Sanches datado de 1754 e que trata do currículo das meninas e da importância de se educarem as filhas de pais honrados para gerirem suas casas ou entrarem para a religião. De acordo com Sanches,

Hua Minina Portugueza ou ha de ser matrona hum dia, ou ha de ser Religioza: a educação que deve ter em casa de seos Pais ou em hua clausura deve ser tal que possa comprir as obrigacoins da Sociedade e Reyno donde naceo, ou as obrigacoins da Religião a que se dedico. ${ }^{12}$

Em uma época de profundas mudanças em relação ao ensino, como foi o século XVIII, a educação formal para meninas em um espaço de clausura para este fim foi recomendada por Ribeiro Sanches. A proposta previa estabelecimentos nos quais se ensinariam matérias específicas às jovens, como por exemplo, gramática para que pudessem escrever cartas, leitura possivelmente para lerem os livros de religião e, o ensino de "contas" (aritmética) para poderem registrar as despesas da casa. A preocupação com a gestão financeira do lar está presente na proposta de educação feminina de Verney ao destacar a importância do ensino de noções de economia doméstica. Quanto a aprender trabalhos manuais, tais como costura, bordado e desenho, segundo o mesmo autor, estas eram habilidades necessárias às mulheres que necessitavam ganhar a vida. ${ }^{13}$ Sobre o ensino de disciplinas como História e Geografia, este também foi recomendado por alguns educadores, enquanto as aulas de latim para meninas foram vistas como uma questão controvertida ao longo da época moderna, geralmente recomendado apenas para as religiosas e mulheres da nobreza. $O$ aprendizado de dança e de canto, por sua vez, eram vistos com bons olhos e justificados para dar graça e elegância às jovens das elites. ${ }^{14}$

Quanto à educação nos recolhimentos femininos da região sudeste da América portuguesa -- os quais estudei mais detidamente -- pode-se dizer

\footnotetext{
${ }^{11}$ SANCHES, Ribeiro. Consequências por não criarem as Mães seus filhos. In: Cartas para a educação da mocidade", op. cit., p. 57e 58.

${ }^{12}$ SANCHES, Ribeiro. Educação de hua Menina ate a idade de tomar Estado, no Reyno de Portugal. escrita a meu Am. .0 Dr. Barbosa a Elvas. Pello anno 1754: nos banhos de Bourbon Lancy , Biblioteca de Madri. Manuscritos de Ribeiro Sanches, I, 256. Apud Luís de Pina. Plano para a educação de uma menina portuguesa no século XVIII. In: Cale: Revista da Faculdade de Letras do Porto, vol 1, 1966, p. 43 (Biblioteca Digital).

${ }^{13}$ VERNEY, op. cit., p. 204.

${ }^{14}$ VERNEY, op. cit., p. 213-214.
} 
que os elementos presentes nas propostas dos dois ilustrados portugueses se encontravam em evidência nessas instituições. É bastante interessante observar que tais princípios tenham cruzado o Atlântico, sendo registrados nos estatutos de alguns desses estabelecimentos ou em seus planos de estudo para meninas.

As jovens residentes em Macaúbas, por exemplo, de acordo com as "Regras dos exercícios cotidianos das nossas porcionistas", ${ }^{15}$ redigidas após 1750, permitem perceber que além da educação religiosa oferecida em horários específicos e nas atividades compartilhadas com o resto da comunidade, como a missa e as orações no coro ou no refeitório, "a maior parte do tempo das educandas do Recolhimento de Nossa Senhora da Conceição de Macaúbas deveria estar voltada para a aprendizagem, quando aprenderiam a ler e a escrever o latim, o português e o francês, além de noções de aritmética e alguns trabalhos manuais". ${ }^{16}$

Por outro lado, a necessidade de se preparar as jovens de diferentes segmentos sociais para as funções domésticas é algo que foi reiteradamente mencionado nos tratados sobre a educação de meninas da época moderna, uma posição que Ribeiro Sanches evidenciou no plano de estudos para esse fim que submeteu ao amigo Barbosa, como pode ser observado abaixo:

O officio de hua Matrona consiste em, saber governar hua Caza com tal regra e economia que os rendimentos della sejão bastantes $p .{ }^{a}$ sustentalla e para establecer a sua familia: deve ser a Mestra do animo dos seos filhos e filhas inculcandolhe hua vergonha eterna pello máo procedimento; e hua estimação ...? pella vida virtuoza. Deve ensinarlhe a cortezia; o asseo a limpeza, a regrar as horas do trabalho, sono, e de comer e de que modo se hão de fazer estas necessárias accosioens da vida. ${ }^{17}$

\footnotetext{
15 "Regras dos Exercícios Cotidianos de Nossas Porcionistas", Apud ROCHA, Adair José dos Santos. A Educação Feminina nos século XVIII e XIX, op. cit., p. 178-180.

${ }^{16}$ ALGRANTI, Leila Escrever, ler e rezar. In: VILLALTA, Luiz Carlos, (org.), dossiê "Bibliotecas, leitura e educação", op. cit. p. 30. Neste artigo apresento de forma mais detalhada aspectos relativos ao plano de estudos das educandas em Macaúbas. Uma versão publicada dos Estatutos das Macaúbas e utilizada neste ensaio encontra-se em anexo ao artigo de ALGRANTI, Leila Mezan. Os Estatutos do Recolhimento das Macaúbas (Norma e contravenção: os bispos de mariana e o cotidiano das reclusas) Minas Gerais, 17451850. In: Revista do Instituto Histórico e Geográfico Brasileiro, ano 161, n. 406, 2000, p. 233-251. Sobre o plano de estudos no recolhimento de Olinda ver: SILVA, Maria Beatriz Nizza da. Educação feminina e educação masculina. In: Revista de História. n. 109, ano XXVIII, 1977, p. 149-163.

${ }^{17}$ SANCHES, Ribeiro. Educação de hua Menina ate a idade de tomar Estado, no Reyno de Portugal. escrita a meu Am. ${ }^{\circ}$ o Dr. Barbosa a Elvas, op. cit., p. 43.
} 
Educar as mulheres para serem mães e esposas era, ao que tudo indi$\mathrm{ca}$, a justificativa mais comum quando se ventilava a proposta de instrução feminina. No caso daquelas que optassem pela vida religiosa, acreditava-se que receberiam educação mais adequada posteriormente. Mas independentemente do estado a ser escolhido na vida adulta, a ideia de educação para as mulheres incluía sempre uma formação religiosa e moral . É , portanto, o caráter de exemplaridade que a mães exerciam na educação dos filhos que se fazia presente quando se defendia a possibilidade de educar e instruir as mulheres na época moderna. Esse é, de fato, o terceiro aspecto geralmente abordado quando se comenta a educação feminina na Colônia, ou na época moderna de forma geral. Uma justificativa adotada, inclusive, por autores dos séculos anteriores como Juan Vives ${ }^{18}$ e Fénelon e que também se apresenta em outros gêneros de escritos destinados a prepará-las para a vida em sociedade. Refiro-me às normas de "bom tom" ou de viver em sociedade, as quais se encontravam dispostas nos manuais de civilidade e em outros gêneros de escritos da época, tais como em instruções dirigidas a jovens da nobreza antes do casamento ou mesmo nos livros de culinária, pois estes últimos incluíam, algumas vezes, informações sobre a arte de estar à mesa e de bem receber. Como bem destacou Maria Alexandre da Câmara, a civilidade era "considerada um domínio do conhecimento tão importante como a leitura, a história ou a geografia". ${ }^{19} \mathrm{E}$ como tal deveria ser transmitida aos jovens de ambos os sexos, como veremos a seguir. ${ }^{20}$

\section{Educação feminina e vida em sociedade}

Segundo Maria Antônia Lopes que estudou as transformações dos papeis femininos na segunda metade do século XVIII em Portugal, a responsável pelo olhar favorável que se começa a dedicar à educação feminina seria a nova forma de sociabilidade entre os sexos. Ensinava-se às jovens, "línguas vivas, literatura, conversação social e leitura de obras dedicadas

\footnotetext{
${ }^{18}$ VIVES, Juan. A instrução de uma mulher cristã (1523). Buenos Aires: Calpe, 1944.

${ }^{19}$ CÂMARA, Maria Alexandre Trindade Gago da. Mundanidade e Quotidiano na cultura portuguesa de Setecentos: escritas codificadas de comportamento. In: Actas do Colóquio Internacional Literatura e História, Porto, 2004, p. 111. A autora apresenta nesse artigo uma discussão sobre os conceitos de cortesia, etiqueta e civilidade evidenciando, entre outros aspectos, que no século XVIII os mesmos já se encontravam cristalizados, sugerindo padrões de comportamento.

${ }^{20}$ De acordo com Antônio Gomes FERREIRA, a Carta de Lei de 6 de Novembro de 1772, promulgada em Portugal, determinava que os mestres de ler, escrever e contar deviam ensinar também "as regras de civilidade em um breve compêndio". Cf. Educação e Regras de convivência e de bom comportamento nos séculos XVIII e XIX. In: História da Educação ASPHE/FAE, Pelotas, v.13, n. 29, set/dez 2009, p.13.
} 
às boas maneiras e à etiqueta". ${ }^{21}$ Pode-se dizer que deste lado do Atlântico se observavam as mesmas mudanças ocorridas na Metrópole e que no final do século XVIII, a vida privada e doméstica também começava a ganhar maior atenção. Conforto e higiene à mesa, por exemplo, passaram a ser itens bastante valorizados e ostentados nos rituais dedicados à alimentação das elites, por meio de um conjunto de artefatos e de gestos que nos revelam as relações das pessoas entre si e das mesmas com as coisas. ${ }^{22}$

A difusão dos tratados de civilidade e de boas maneiras é, portanto, um bom exemplo desse interesse e atenção depositados nas formas de sociabilidade no Antigo Regime e têm sido explorados largamente pelos historiadores, permitindo vários tipos de abordagens sobre as práticas sociais na América portuguesa. O que gostaria de destacar aqui é o caráter pedagógico evidente de tais obras em relação ao modo de se portar em sociedade, pois permitem perceber que nos domínios da vida privada -- assim como ocorria no espaço público -- as diferenças de gênero se construíam cotidianamente, uma vez que homens e mulheres (maridos e esposas) possuíam atribuições e atividades distintas no universo doméstico e não apenas no espaço público. Essas não eram estáticas e se encontravam em permanente transformação, alterando também continuamente as relações de gênero no ambiente doméstico.

Vista nessa perspectiva, "a mesa" ou o que ela representa em termos de práticas sociais e culturais (a comensalidade) se torna um espaço privilegiado de observação do historiador, pois embora as funções de gestão da casa fossem na época prioritariamente atividades femininas, grande parte das ações de cortesia presentes no rituais das refeições estava a cargo dos homens. Isso é válido tanto na tarefa de recepcionar os convidados à mesa, função que cabia ao chefe da casa, como também naquelas dedicadas a trinchar a carne, ou servir os alimentos e o vinho aos convivas. Às esposas cabiam outras funções, geralmente adjacentes ou complementares àquelas do marido. De qualquer modo, ambos precisavam ser instruídos a fim de desempenharem as tarefas que a sociedade esperava que cumprissem.

\footnotetext{
${ }^{21}$ LOPES, Maria Antônia. Mulheres, espaço e sociabilidade - a transformação dos papeis femininos em Portugal à luz de fontes literárias. Lisboa: Livros Horizontes, 1989, p. 98

${ }^{22}$ Sobre as mudanças no ritual das refeições, bem como nas formas de alimentação no século XVIII ver: CAMPORESI , Piero. Hedonismo e exotismo, a arte de viver na época das Luzes. São Paulo: Editora da Unesp, 1996. Sobre o serviço e os artefatos de mesa no Rio de Janeiro, no século XVIII, ver ALGANTI, Leila. Notas sobre alimentação e cultura material no Rio de Janeiro dos vice-reis: diversidade de fontes e possibilidades de abordagens. Conferência proferida no II Seminário Internacional Elementos materiais da cultura e patrimônio, FAFICH/UFMG, abril de 2014 .
} 
Vejamos, então, dois exemplos de fontes escritas que podem nos fornecer uma visão mais ampla da educação feminina na época e dos diversos domínios que esta envolvia. Os documentos escolhidos para análise foram compostos com o objetivo ensinarem os jovens a viverem em sociedade.

o primeiro exemplo foi retirado de um manual de boas maneiras intitulado Escola de Política ou tractado pratico da civilidade portugueza, publicado em 1786, no Porto, de autoria do cônego D. João de Nossa Senhora da Porta Siqueira e se refere à comensalidade, ou seja, um aspecto bastante importante da sociabilidade da época moderna, o qual exigia um conjunto de normas que deveriam ser interiorizadas pelos jovens de ambos os sexos, quer vivessem no Reino, quer na Colônia. Embora dirigido aos meninos, o autor estendeu várias de suas instruções e comentários também às meninas e considerou as regras de cortesia um setor importantíssimo da educação dos políticos e dos cortesãos para suas ações na vida civil. ${ }^{23 .}$

No prólogo da obra, Porta Siqueira informou ter se inspirado em escritos de autores das nações civilizadas para acompanhar a tradução da obra de Blancard, Escola de bons costumes, a qual se debruçava sobre aspectos da educação moral. Como bem observou, Antônio Gomes Ferreira, nestas obras de boas maneiras havia "uma nítida intenção de interligar a educação moral e religiosa com a da civilidade". ${ }^{24}$

O tratado de D. João da Porta Siqueira foi organizado em doze capítulos e em três deles o autor se ateve a matérias vinculadas às tarefas domésticas e de administração do lar, nas quais se esperavam procedimentos do senhor ou da senhora da casa. São esses: "do modo de fazer visitas; meza e assembléa”. Mesmo levando-se em conta que o tratado foi escrito para a instrução dos meninos, a ausência de referências explícitas às funções domésticas femininas é facilmente notada. É o senhor da casa, por exemplo, quem se destaca nas recepções sociais ou à mesa. É ele também quem acompanha as visitas até à escada ou à porta, levanta os brindes e, se for o caso, designa os pares das danças em um encontro social. ${ }^{25}$ É, porém, no serviço da mesa que se observa mais especificamente a distinção de gênero presente nos espaços da casa, onde por exemplo, a sala de jantar se apresenta, como um local de

\footnotetext{
${ }^{23}$ SIQUEIRA, D. João de Nossa Senhora da Porta. Escola de Política ou tractado pratico da civilidade portugueza na officina de Antonio Alvarez Ribeiro, Lisboa, 1786.

${ }^{24}$ FERREIRA, Antônio Gomes. Educação e Regras de convivência e de bom comportamento nos séculos XVIII e XIX. I: História da Educação ASPHE/FAEPel, Pelotas, v.13, n.29, p. 9-28, set/dez 2009. Disponível em: http//fae.ufpel.edu.br/asphe. Acesso em 13/04/2014.

${ }^{25}$ SIQUEIRA, op. cit., p. 91.
} 
domínio e de exibição predominantemente masculino, no qual as ações de destaque caberiam aos homens, como também enfatizou Tania de Andrade Lima para o Rio de Janeiro do século XIX. ${ }^{26}$ Ao que tudo indica, até este período, apenas na ausência do dono da casa tais funções seriam desempenhas pelas mulheres, o que significa que elas também deveriam ser instruídas, mesmo que fosse para substituí-los ocasionalmente.

Referindo-se ao protocolo de mesa, por exemplo, Porta Siqueira informa sobre o senhor da casa:

O seu lugar he onde lhe parece, mas nunca os melhores, o mesmo digo da Senhora. Deve ir á Salla, onde estão os convidados, conduzi-los para a mesa, destinar-lhes os lugares, segundo o sexo, o estado, e as graduações, ao menos as principaes, deixando aos outros a escolha. Benzer a mesa, ou pedir a algum Sacerdote, se está presente, que o faça, porque este foi sempre hum louvavel costume entre os Portuguezes, ainda que infelizmente se vai perdendo; da mesma sorte dar graças a Deos no fim, e fazer as mais honras do banquete, pedir que desdobrem o guardanapo, trinchar, mostrar os pratos mais delicados, fazer que sejão servidos promptamente, animar o convite, e da-lo por acabado, quando for tempo, conduzi-los ao Dessert, ao lugar do café. A Senhora também deve trinchar, sabendo. ${ }^{27}$

De acordo com o tratado, era ainda ao dono da casa que pertencia principalmente a tarefa de trinchar as carnes, o qual poderia atribuir a outros essa função, a fim de não passar pela vergonha de dizer que não sabia. Por esse motivo, Siqueira apregoava que todo cavalheiro deveria aprender a cortar "as viandas com método e ter conhecimento dos melhores bocados de cada peça, a fim de os servir com decência"28. No mesmo capítulo o autor dedicou-se também a ensinar as formas de comer e de utilizar os utensílios disponíveis à mesa, deixando bastante claro que aprender as regras de civilidade era parte integrante do processo de educação de meninos e meninas, quer a instrução ocorresse em casa ou em estabelecimentos de ensino.

Mas se as funções à mesa eram coordenadas pelo senhor da casa, havia um número considerável de atribuições domésticas e também sociais que cabiam às esposas inspecionar ou desempenhar. A importância

\footnotetext{
${ }^{26}$ LIMA, Tânia de Andrade .Pratos e mais prato: louças domesticas , divisões culturais e limites sociais no Rio de Janeiro, século XIX. Anais do Museu Paulista: nova série, v.3, jan/dez. 1995. p. 136. Eliane Moreli argumenta que os inventários de Campinas do século XIX, de homens sem esposas o ambiente da casa era muito simples e despojado de luxo. Conclui que se a sala de jantar era um espaço masculino, o serviço de louça, os arranjos de mesa, e as toalhas ligavam-se ao universo feminino. Cf. MORELI, Eliane. Morar e Viver na cidade - Campinas (1850-1900). São Paulo: Alameda, 2010, p. 151.

${ }^{27}$ SIQUEIRA, op. cit., p. 144.

${ }^{28}$ Ibidem, p. 146.
} 
de bem instruir uma jovem da nobreza portuguesa para tais tarefas pode ser observada em um conjunto de escritos da Marquesa de Alorna (17501839) compilados por Hernani Cidade e intitulados Os deveres da dona de casa (Cartas da Condessa de Oeynhausen a uma filha que vai casar). ${ }^{29}$ Os conselhos ou instruções foram redigidos na forma de cartas e tinham como objetivo advertir a filha sobre as principais tarefas que em breve lhe caberiam. 0 próprio Hernani Cidade teve dúvidas em relação a qual das filhas a marquesa se dirigia, e estimou que o documento seria de $1799 .{ }^{30}$

Não cabe aqui tratar do gênero epistolar e de sua importância na comunicação escrita, bem como na literatura do século XVIII de forma geral, algo que tem sido muito bem estudado por especialistas no assunto. ${ }^{31}$ Também não cabe enveredar pela discussão sobre correspondências que foram escritas "para não serem enviadas e cartas realmente enviadas", um aspecto interessantíssimo desse gênero literário, como mencionado por Vanda Anastácio na apresentação do livro Correspondências, usos da carta no século XVIII. Mas não podemos deixar de notar que instruções e mesmo lições em forma de cartas ou de diálogos foi uma opção à disposição dos educadores da época, como no caso de Verney e de Ribeiro Sanches que optaram pela forma epistolar de comunicação. ${ }^{32}$ Afinal, a carta era "uma forma de criação, difusão e promoção de ideias e a correspondência podia ser posta a serviço desses objetivos", como bem esclareceu Raquel Vazques. ${ }^{33}$

A Marquesa de Alorna é uma personagem da nobreza portuguesa do século XVIII, famosa por suas habilidades literárias e pela educação peculiar recebida ao longo da infância e da juventude, como prisioneira no Convento

\footnotetext{
${ }^{29}$ ALORNA, Marquesa de (Leonor de Almeida Portugal de Lorena e Lencastre). Inéditos: cartas e outros escritos. Prefácio de Hernani Cidade. Lisboa: Livraria Sá da Costa, 1941.

${ }^{30} \mathrm{~A}$ qual das filhas da Condessa foram escritas estas cartas, pergunta o autor da compilação. Conclui que das duas únicas que casaram - D. Leonor com o Marquês de Fronteira, em 1799 e D. Juliana, com o Conde da Ega, em 1795, é a primeira a que pela altura dos 17 anos ainda era solteira.

${ }^{31}$ Ver por exemplo, ANASTÁcIO, Vanda. Correspondências - usos das carta no século XVIII. Lisboa: Edições Colibri/Fundação das Casas de Fronteira e Alorna, 2005

${ }^{32}$ A obra Tesouro de Meninas (1757), de Jeanne Marie Leprince de Beaumont é um exemplo de compêndio de educação feminina escrito na forma de diálogos, o qual continha lições com conteúdos variados, desde ciências e humanidades, à moral, religião e etiqueta. A obra circulou na América portuguesa no idioma original, como apontou Jocilene Pereira Lima em estudo dedicado a esse compêndio, no qual evidencia que o modelo e formato de escrita em forma de diálogos se inspirou em obras bem mais antigas, o que permite pensar em uma tradição nessa forma de transmissão de conteúdos. Ver da autora: LIMA. Jocilene Pereira. Uma história dos compêndios didáticos Tesouro de Meninos e Tesouro de Meninas no Brasil. Dissertação de Mestrado. João Pessoa: Universidade Federal da Paraíba, Programa de Linguística, 2013.

${ }^{33}$ VAZQUES, Raquel. Privacidade e publicidade: a correspondência pessoal como forma de intervenção nos campos intelectual e do poder. In: ANASTÁCIO, Vanda. Correspondências, op. cit., p. 78.
} 
de Chelas, juntamente com a mãe, durante o período pombalino. Seus escritos tem sido objeto de importantes estudos na área da literatura, tarefa que estamos longe de pretender realizar..$^{34} \mathrm{O}$ que nos interessa destacar nessas cartas são as representações que a autora oferece sobre a educação de uma menina nobre no período estudado e como ela se valeu do gênero epistolar para tratar de um conjunto de atividades domésticas femininas, as quais embora se desenvolvessem majoritariamente no espaço privado do lar, poderiam repercutir na imagem pública feminina, já que esta deveria ser bem cuidada e preservada.

As cartas da Marquesa de Alorna à sua filha se estendem, portanto, além do estreitamento dos laços entre elas e podem ser entendidas como uma forma de intervenção no campo da moral feminina. ${ }^{35}$ Daí sua importância para refletirmos sobre as representações da sociedade portuguesa em relação às mulheres e sua consequente educação, no final do século XVIII, no império português.

No conjunto das seis cartas da Marquesa de Alorna compiladas por Hernani Cidade sobre os deveres da dona de casa destacam-se, a nosso ver, três grandes temas referentes à educação das mulheres:

Primeiramente, um conjunto de advertências relacionadas aos cuidados de si, ligadas não apenas ao corpo feminino mas também à moral, as quais abordam desde os cuidados com a beleza e a higiene, aos exercícios físicos e os divertimentos. Todos esses temas são objetos da primeira carta. Em síntese, o que a marquesa recomendava às jovens senhoras da nobreza portuguesa era moderação e equilíbrio em todas as atitudes: aconselhava-as a uma vida ativa e regrada. Ou seja, nada da mulher estar o dia todo deitada sem ocupação ou, ao contrário, com uma agenda social repleta de divertimentos. $O$ segundo conjunto de instruções presente nas cartas 5 e 6 aborda os riscos das futilidades exageradas e o desembaraço excessivo no trato com os homens, atitudes que poderiam levar a mal entendidos e às criticas da sociedade, segundo a marquesa. Ou seja, tais instruções foram dedicadas aos cuidados com a honra feminina.

As cartas dois, três e quatro, por sua vez, tratam dos cuidados com a casa e com os serviçais, atividades consideradas tanto pela marquesa, quanto por Ribeiro Sanches como extremamente importantes na educação de uma

\footnotetext{
${ }^{34}$ Bibliografia da Alcipe http://www.fronteira-alorna.pt/pdf/bibliografia_alcipe.pdf. Acesso: 15/11/2014. ${ }^{35}$ Sobre os usos das cartas no século XVIII, ver: ANASTÁcIO, op. cit., p. 9-11.
} 
senhora da nobreza. As instruções da marquesa de Alorna nesse campo se basearam na noção de economia: economia de tempo, economia de espaço e economia doméstica. São essas que nos interessam comentar brevemente, pois vinculam-se diretamente à necessidade de se educar as meninas para as funções domésticas e da vida em sociedade.

Nas cartas referentes à gestão da casa dois aspectos chamam atenção. o primeiro diz respeito ao controle do tempo. Isso porque as atividades de uma dona de casa seriam tantas que sem um planejamento adequado das horas do dia, não seria possível dar conta de tudo. Poderíamos dizer que a marquesa de Alorna apresenta à sua filha - e às jovens da sua condição social em geral - um plano de ação com as atribuições divididas em função do tempo. Algo muito semelhante à divisão das horas existente nos estatutos das instituições de reclusão feminina na Colônia. A diferença fundamental parece ser a ausência do sino para regular e controlar os horários, pois a disciplina, a exemplo do que sucedia nos recolhimentos de mulheres, seria a única forma de se escapar à ociosidade. Esta última era considerada na época, a grande vilã na vida de uma jovem honrada. Daí a importância de se promover o desenvolvimento de certas habilidades nas jovens (como escrita, leitura, costura, bordado, desenho), pois além de mantê-las ocupadas, as ajudaria a desempenharem adequadamente suas futuras funções na sociedade. De acordo com a marquesa de Alorna,

Uma mãe de família necessita de tempo para meditar e recapitular os seus
deveres; para implorar a misericórdia divina e o poder do Céu; para o governo
doméstico; para a cultura dos seus talentos, penhores sagrados que deve
transmitir a seus filhos. Necessita de tempo para satisfazer às obrigações
que se contraem na sociedade e para recreio honesto, estabelecido entre
as pessoas da sua classe. Além disso, é indispensável a uma mulher de bem
destinar alguns para cumprir as obras de misericórdia, tão necessárias ao
caráter de cristã como ao de humana, pois a besta feroz que não vive senão
para si, deveria envergonhar-se de gozar dos privilégios da sociedade, e
solicitar uma caverna, onde à maneira dos tigres, seus semelhantes, fosse
fartar-se de egoísmo e barbaridade. ${ }^{36}$

Após tão contundente defesa da necessidade de controlar o tempo, segue-se uma proposta de planejamento das atividades divididas entre o período da manhã e da tarde. Recomendava-se, portanto, acordar cedo, sendo que das sete às oito horas, o tempo deveria ser dedicado à toilette da manhã

\footnotetext{
${ }^{36}$ ALORNA, Marquesa de (Leonor de Almeida Portugal de Lorena e Lencastre). Inéditos: cartas e outros escritos. Prefácio de Hernani Cidade, op. cit., carta número 2, p. 79-80.
} 
e ao estudo sobre o que pudesse interessar à jovem dona de casa. Das oito às nove, a senhora deveria se dedicar ao almoço (café da manhã), à família e aos arranjos domésticos; Das nove às dez horas era a vez das artes e, das dez até ao meio dia, a jovem mãe deveria estar atenta aos filhos. Do meio dia até a hora do jantar (o nosso almoço), "são incalculáveis as ocorrências", advertia a marquesa de Alorna e por isso a dona de casa deveria estar "livre, desembaraçada e vestida, para acudir a tudo o que ocorrer ou seja do agrado de seu marido, ou conveniente a si ou a qualquer pessoa que dependa dele". Referindo-se, portanto, ao final da manhã, a instrução da marquesa era clara:

\begin{abstract}
essas são as horas em que também pode ter lugar a costura, o bordado, e às vezes a música, à qual deve V. consagrar, pelo menos, meia hora cada manhã. Toda a pessoa que quiser viver feliz e ùtilmente, deve arranjar-se de modo que as manhãs lhe fiquem inteiramente livres para si, e as tardes para consagrar aos outros; porque, se as horas da manhã se perdem para o estudo e para os negócios, pouco ou nenhum proveito se tira das tardes. ${ }^{37}$
\end{abstract}

Quanto ao período da tarde, esse seria o espaço de tempo no qual a ociosidade "triunfa", advertia a emissora das instruções à uma jovem prestes a se casar. Daí a necessidade estar atenta aos galanteios que pudessem surgir, bem como ao excesso de visitas pois, "os lisonjeiros, os elegantes, os ociosos, bem brunidos, bem contentes de si, passam de uma casa a outra, ora a felicitar uma senhora do dia dos seus anos, outra do seu feliz parto, aquela de um despacho, esta outra de um casamento (...)". Assim, após mais alguns avisos sobre a organização do tempo a autora conclui que "Um juízo claro e uma constante modéstia é quem determina o tempo que se pode perder com a sociedade inútil(...)". ${ }^{38}$

Quanto às atividades domésticas de uma senhora da nobreza, destacadas pela marquesa de Alorna, nos chamou atenção a ausência de um comentário mais específico sobre a relação da dona da casa com os rituais das refeições, bem como com a forma de recepcionar os convidados. Mas, conforme apontado por Porta Siqueira, estas seriam atribuições do marido. No entanto, segundo a autora das instruções, em uma casa grande deveria haver um mordomo para inspecionar e administrar o conjunto das atividades, bem como os demais empregados. Para isso esclarecia que o mordomo deveria ter "um livro de razão, aonde se lancem todos os dias as despesas da cozinha, cavalariça, adega e copa”. Porém, cada um dos chefes destes ofícios

\footnotetext{
${ }^{37}$ Ibidem, p. 80.

${ }^{38}$ Ibidem , p. 81.
} 
também deveria ter um livro particular para registrar as despesas do seu setor doméstico, a fim de se confrontar os dados com aqueles presentes no livro do mordomo. E, ao final do mês, a dona da casa deveria controlar os cadernos de anotações e "destinar uma hora para examinar individualmente o preço dos gêneros, compará-los com aqueles divulgados na imprensa e , havendo excesso, corrigi-los". 39

Ao encerrar a questão da gestão doméstica, a marquesa de Alorna conclui que se todos os artigos que formam o plano da economia do tempo, da economia do espaço e da economia doméstica fossem cumpridos, as mulheres no geral, e no caso a filha em especial, conseguiriam sem dúvida formalizar um governo bem regulado de suas casas. Um tema que, conforme foi visto, era recorrentemente enfatizado nos diferentes tipos de escritos dedicados à educação feminina ao longo da época moderna.

\section{Considerações finais}

Os três pontos mencionados no início desse estudo referentes às abordagens da historiografia sobre a educação de meninas na América portuguesa, isto é: os poucos espaços institucionalizados para a instrução de meninas; os currículos diferentes de acordo com o sexo dos estudantes; e a proposta de educar as mulheres para melhor desempenharem suas funções familiares e domésticas, se ligam às expectativas da sociedade em relação a elas na Colônia. Nesse sentido, a exemplo do que também sucedia em Portugal, a educação no espaço doméstico acabou por assumir um caráter bastante importante, uma vez que poucas jovens conseguiam ter acesso á uma instrução institucionalizada. Dessa forma, o aprendizado mais comum consistia na observação das mulheres da casa nas suas atividades do dia a dia e, quando muito, no caso de jovens das elites, alguma atenção era dada ao ensino das primeiras letras.

Cabe ressaltar, entretanto, que embora o espaço doméstico fosse por excelência um domínio feminino defendido desde os textos medievais, (Christine de Pisan, por exemplo) o discurso em defesa de uma educação feminina voltada para a construção da imagem da boa mãe-dona-de-casa só foi interiorizado plenamente pelas mulheres no século XIX e encontra-se, a nosso ver, associado ao crescimento do sentimento de vida privada ou de intimidade doméstica, noção bastante explorada nos tratados de educação feminina do século XIX, bem como nas revistas e livros de cozinha dirigidos

${ }^{39}$ Ibidem, carta número 4, p. 87. 
às mulheres, os quais tiveram uma grande divulgação nesse período. Isto significa dizer que se os temas do discurso sobre a educação feminina foram recorrentes ao longo da época moderna - seja em Portugal, seja na América portuguesa - seu impacto e receptividade não foram sempre os mesmos e mudaram de um período a outro. ${ }^{40}$

Assim, a hipótese que norteou esse trabalho sobre a educação de meninas no século XVIII - e que tenho perseguido em outros estudos - é que somente com as transformações que ocorreram na vida privada, no século XIX, as mulheres foram ocupando integralmente os domínios da esfera doméstica e o comando de seus rituais, desalojando os homens de alguns de seus lugares tradicionais de atuação. Acredito que dando continuidade a proposta aqui iniciada de comparar estatutos de instituições de ensino, manuais de civilidade e tratados de educação feminina do século XVIII com aqueles disponíveis para os séculos XIX e XX será possível avançar nessa ideia e distinguir nos meandros de um discurso que aparenta ser uma ladainha sem fim através dos séculos, aquilo que foi específico de cada época.

Artigo recebido para publicação em 19/11/2014 Artigo aprovado para publicação em 20/11/2014

\footnotetext{
${ }^{40}$ A receptividade das ideias de Rousseau, divulgadas no Emilio, no final do século XVIII e durante todo o século seguinte, indicam o modelo a ser seguido pelas mulheres burguesas especialmente. Sobre essa questão ver ALGRANTI, Leila. Honradas e Devotas, op. cit., pp. 245-246.
} 